OPEN ACCESS

Edited by:

Guillaume Mabilleau,

Université d'Angers, France

Reviewed by:

Stéphane Blouin,

Ludwig Boltzmann Institute of

Osteology (LBIO), Austria

Jan Josef Stepan,

Charles University, Czechia

*Correspondence:

Hiroshige Sano

hsano@med.niigata-u.ac.jp

Specialty section:

This article was submitted

to Bone Research,

a section of the journal

Frontiers in Endocrinology

Received: 25 December 2017

Accepted: 23 February 2018

Published: 19 March 2018

Citation:

Sano H, Kondo N, Shimakura T,

Fujisawa J, Kijima Y, Kanai T,

Poole KES, Yamamoto N, Takahashi HE and Endo N (2018) Evidence for Ongoing ModelingBased Bone Formation in Human

Femoral Head Trabeculae via Forming Minimodeling Structures:

A Study in Patients with

Fractures and Arthritis.

Front. Endocrinol. 9:88.

doi: 10.3389/fendo.2018.00088

\section{Evidence for Ongoing Modeling- Based Bone Formation in Human Femoral Head Trabeculae via Forming Minimodeling Structures: A Study in Patients with Fractures and Arthritis}

\author{
Hiroshige Sano ${ }^{1,2,3 *}$, Naoki Kondo', Taketoshi Shimakura², Junichi Fujisawa', \\ Yasufumi Kijima ${ }^{1}$, Tomotake Kanai', Kenneth E. S. Poole ${ }^{3}$, Noriaki Yamamoto ${ }^{2,4}$, \\ Hideaki E. Takahashi ${ }^{2,4}$ and Naoto Endo
}

${ }^{1}$ Division of Orthopedic Surgery, Department of Regenerative and Transplant Medicine, Niigata University Graduate School of Medical and Dental Sciences, Niigata, Japan, ${ }^{2}$ Niigata Bone Science Institute, Niigata, Japan, ${ }^{3}$ Department of Medicine, University of Cambridge, Cambridge, United Kingdom, ${ }^{4}$ Department of Orthopedic Surgery, Niigata Rehabilitation Hospital, Niigata, Japan

Bone modeling is a biological process of bone formation that adapts bone size and shape to mechanical loads, especially during childhood and adolescence. Bone modeling in cortical bone can be easily detected using sequential radiographic images, while its assessment in trabecular bone is challenging. Here, we performed histomorphometric analysis in 21 bone specimens from biopsies collected during hip arthroplasty, and we proposed the criteria for histologically identifying an active modeling-based bone formation, which we call a "forming minimodeling structure" (FMiS). Evidence of FMiSs was found in 9 of 20 specimens (45\%). In histomorphometric analysis, bone volume was significant higher in specimens displaying FMiSs compared with the specimens without these structures (BV/TV, $31.7 \pm 10.2$ vs. $23.1 \pm 3.9 \% ; p<0.05)$. Osteoid parameters were raised in FMiS-containing bone specimens (OV/BV, $2.1 \pm 1.6$ vs. $0.6 \pm 0.3 \%$; $p<0.001, \mathrm{OS} / \mathrm{BS}, 23.6 \pm 15.5$ vs. $7.6 \pm 4.2 \% ; p<0.001$, and O.Th, $7.4 \mu \mathrm{m} \pm 2.0$ vs. $5.2 \pm 1.0 ; p<0.05)$. Our results showed that the modeling-based bone formation on trabecular bone surfaces occurs even during adulthood. As FMiSs can represent histological evidence of modeling-based bone formation, understanding of this physiology in relation to bone homeostasis is crucial.

Keywords: modeling-based bone formation, forming minimodeling structures, femoral head, bone histomorphometry, femoral neck fracture, rheumatoid arthritis, hip osteoarthritis

\section{INTRODUCTION}

Despite significant effort over recent decades, the histological finding of modeling-based bone formation on trabecular bone still remains elusive. Bone modeling is the biological process that shapes and sizes bone in response to physiological influences or mechanical forces encountered by the skeleton, and is essential especially during skeletal growth $(1,2)$ and reaction to 
mechanical loading $(3,4)$. In bone modeling, bone resorption and bone formation are not necessarily coupled in a sitespecific manner, as they are in the process of remodeling-based bone formation (3-7).

Frost first proposed that the process of modeling-based bone formation could be identified in trabecular bone under the microscope, and termed this "minimodeling" $(2,8)$. Some authors have reported the phenomenon of minimodeling in postmenopausal women during teriparatide $(\mathrm{PTH})$ treatment $(9,10)$, in uremic patients (11-15), and in rats treated with prostaglandin E2 (16) and vitamin D3 $(17,18)$. These were from the histological evidence of bone formation upon a smooth cement line. However, we propose that the definition of modeling-based bone formation should not rely on the characteristics of the cement line (smooth or scalloped). This is because cement lines are typically associated with the resorption of primary or secondary bone corresponding to the extent of osteoclastic Howship's lacunae at the periphery of secondary osteons (19), which is not appropriate when considering the process of modeling-based bone formation.

In this study, we clarified the definition of the structure for modeling-based bone formation and defined this histological appearance as a "minimodeling structure" (MiS), because the original description of minimodeling referred to the process of bone formation (2). We further proposed the term "forming minimodeling structure" (FMiS) for the MiS covered with an osteoid seam, which represents an active state in bone formation (20). We then performed histomorphometric analyses in bone biopsies from the femoral heads of patients with femoral neck fracture (FN), rheumatoid arthritis (RA), and osteoarthritis (OA). In particular, we investigated bone histomorphometric parameters in specimens with and without FMiSs to evaluate the histological differences between these groups, which could provide a better understanding of the underlying mechanism of trabecular bone modeling.

\section{MATERIALS AND METHODS}

\section{Specimens}

Our analysis was performed on 21 femoral heads obtained from 20 Japanese adults who underwent total hip arthroplasty or femoral head replacement at Niigata University Hospital and Niigata Rehabilitation Hospital. Written informed consent was obtained from each patient in accordance with the ethics committee of Niigata University Medical and Dental Hospital, and Niigata Rehabilitation Hospital. This study was in compliance with the standard guidelines for human research (Declaration of Helsinki).

\section{Undecalcified Histology}

After fixing with $70 \%$ ethanol, a bone block of $10 \mathrm{~mm} \times$ $10 \mathrm{~mm} \times 10 \mathrm{~mm}$ was excised from the central region of the femoral head, encompassing purely trabecular bone (Figure 1). Villanueva bone staining was performed according to a previously reported protocol (21). Thereafter, the excised tissue was dehydrated in ascending grades of ethanol and acetone, and subsequently infiltrated and embedded in methylmethacrylate

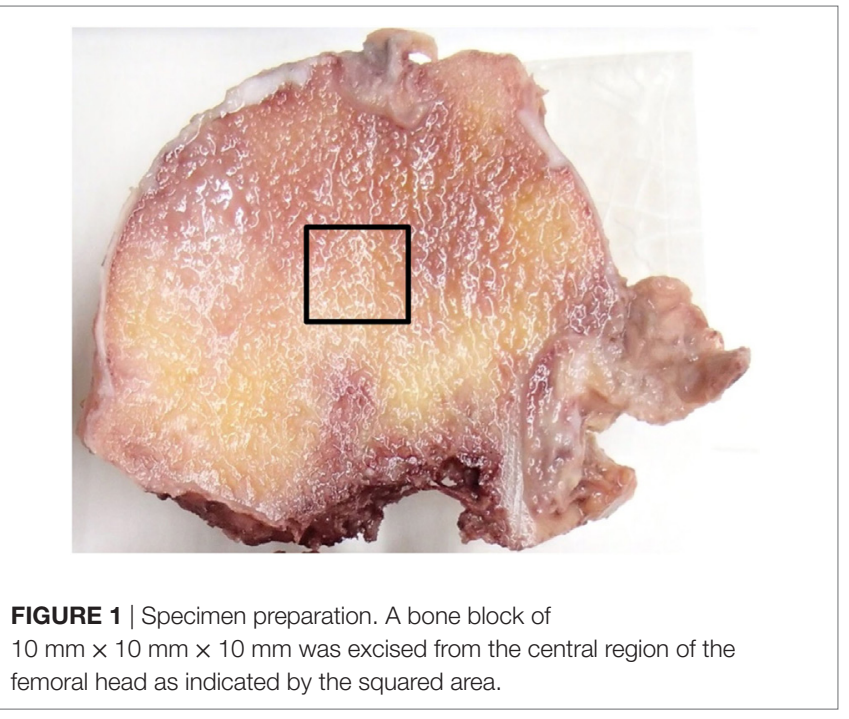

without decalcification. The resulting blocks were then sectioned at a thickness of $5 \mu \mathrm{m}$ by microtome (Leica RM2255). A single $10 \mathrm{~mm} \times 10 \mathrm{~mm}$ section from the sagittal midplane was selected from each sample.

\section{Quantitative Conventional Static Histomorphometry}

Bone histomorphometric measurements were performed as previously described $(7,22,23)$. Briefly, the bone structural unit was identified under the polarized light microscope. Measurements were then performed using a semiautomatic image analyzing system (Histometry RT CAMERA, System Supply, Nagano, Japan) with a $20 \times$ objective lens and one set of $10 \times$ oculars, and at $200 \times$ magnification. Analyses of the structural parameters [bone volume/tissue volume (BV/TV, \%), trabecular thickness (Tb. Th, $\mu \mathrm{m})$ ], the static formation parameters [osteoid volume/bone volume (OV/BV, \%), osteoid surface/bone surface (OS/BS, \%), osteoid thickness $(\mathrm{O} . \mathrm{Th}, \mu \mathrm{m})]$, and the static resorption parameter [eroded surface/bone surface (ES/BS, \%)] were carried out according to the standards of the American Society for Bone and Mineral Research $(24,25)$.

\section{Forming Minimodeling Structure}

We referred to the histological finding of the modeling-based bone formation on trabecular bone with no evidence of previous resorption as a MiS. We proposed the following histological criteria for the definition of the MiS: (a) the base of the MiS is a smooth lamellar bone surface, and (b) the lamellar pattern of the MiS is different from that of the base of the bone surface (Figures 2A-D). We suggested the following histological criteria to define a "FMiS" (Figures 2E-H): (a) the surface of the MiS is covered with an osteoid seam of at least $3-\mu \mathrm{m}$ thickness under polarized light microscopy (Figure 2F), and (b) the degree of fluorescent signal in bone in the MiS is different and lower than that of older adjacent bone as observed in Figure 2G (arrowheads). This is due to its relatively lower mineralization, which was confirmed by comparison with contact micro-radiograph 


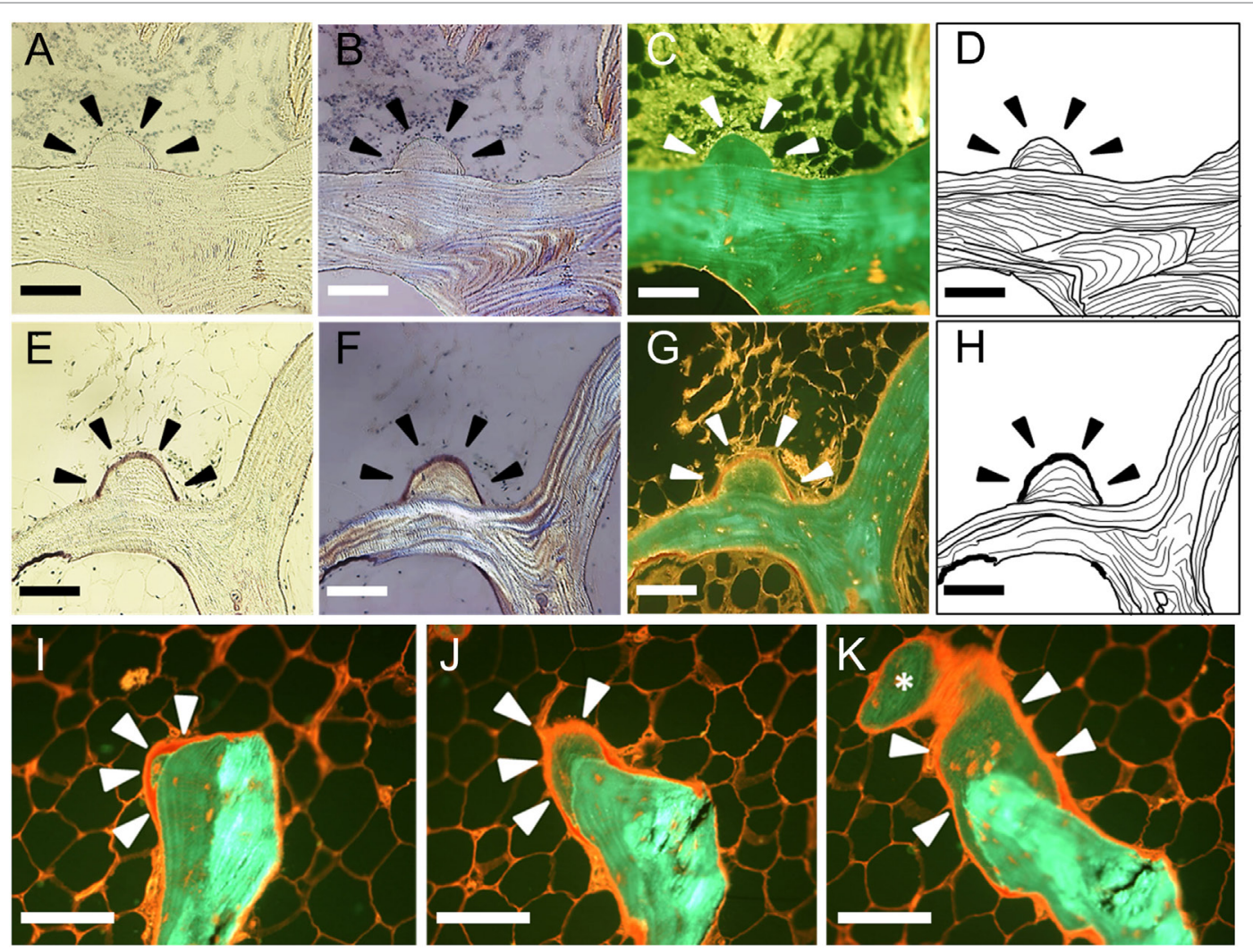

FIGURE 2 | Histological findings in minimodeling with and without osteoid seam. A minimodeling structure (MiS) without an osteoid seam (A-D). Arrowheads indicate the representative MiS. The base of the MiS is a smooth lamellar bone surface without any evidence of previous osteoclastic Howship's lacunae. The lamellar pattern of the base is different from that of the MiS. A forming minimodeling structure (FMiS) (E-H). An osteoid seam was detected on the MiS surface as purple under polarized light microscopy [(F), arrowheads], and red under fluorescent microscopy [(G), arrowheads]. The degree of fluorescent signal in the FMiS was lower than that of the base (G). An analysis of consecutive sections [(I-K); I $\rightarrow J \rightarrow \mathrm{K}$. An FMiS was detected on the smooth bone surface without evidence of previous bone resorption (I), which showed growth $\mathbf{( J )}$ and connection to the adjacent trabecular bone as indicated by an asterisk (K). Bright-field microscopy $\mathbf{( A , E ) ; ~ p o l a r i z e d ~ l i g h t ~ m i c r o s c o p y ~ ( B , F ) ; ~ f l u o r e s c e n t ~ m i c r o s c o p y ~ ( C , G , I - K ) ; ~ d i a g r a m ~ o f ~ t h e ~ M i S ~ ( D , H ) . ~ S c a l e ~ b a r s : ~} 100 \mu \mathrm{m}$.

(Figure S1 in Supplementary Material). To visualize the FMiS in $3 \mathrm{D}$, we performed an additional analysis of 30 consecutive sections in 1 specimen with evident FMiSs, focusing on the FMiS. In histomorphometric analysis, we investigated the number of FMiSs/total bone surface (N.FMiS/ $\mu \mathrm{m})$, and the bone volume [BV (FMiS)] and bone surface [BS (FMiS)] of FMiSs in each FMiS-containing specimen. Using the result of conventional static histomorphometry, BV (FMiS)/BV (\%), BV (FMiS)/OV (\%), BS (FMiS)/BS (\%), and BS (FMiS)/OS (\%) were calculated.

\section{Analysis of the Specimens from Patients}

Age, body mass index (BMI), diagnosis for hip surgery, therapies for osteoporosis (OP) and RA, respectively, were analyzed in each patient. In patients with RA, we also analyzed disease activity score (DAS) 28-ESR3 $(26,27)$, blood serum level of C-reactive protein (CRP) and matrix metalloproteinase-3 (MMP-3), and dose of prednisolone (PSL). We conducted three analyses with conventional static histomorphometry: (a) comparison between the specimens with $(n=9)$ and without FMiSs $(n=11)$, (b) comparison between the RA specimens with $(n=7)$ and without FMiSs $(n=6)$, and (c) among specimens from patients with
RA who had hip surgery due to joint destruction, comparison between these with $(n=6)$ and without FMiSs $(n=3)$.

\section{Statistical Analysis}

Mann-Whitney sum rank tests were used. Data are expressed as the mean \pm SD. All the analyses were performed by using GraphPad Prism software (GraphPad, La Jolla, CA, USA). $p$-Value $<0.05$ was considered statistically significant.

\section{RESULTS}

\section{Characteristics of the Patients}

This study included 21 specimens from 20 patients (Table 1). Of these, 1 patient underwent bilateral hip surgery (Case 3, No. 14, 15), and 1 femoral head specimen from a male patient with RA was excluded from our analysis due to the unreliability of the histomorphometric analysis from the extent of joint destruction (Case 9, No. 21). Patients included in the analysis ranged from 27 to 90 years of age (mean \pm SD, $69.3 \pm 16.2$ years), with 16 women (84\%) and 3 men (16\%). There were eight patients using 
TABLE 1 | Characteristics of the patients.

FMiS-positive group

\begin{tabular}{|c|c|c|c|c|c|c|c|c|c|c|c|c|c|}
\hline \multirow[b]{2}{*}{ Case } & \multirow[b]{2}{*}{ No. } & \multirow[b]{2}{*}{ Sex } & \multirow[b]{2}{*}{ Age } & \multirow[b]{2}{*}{ Diagnosis } & \multicolumn{2}{|c|}{ Therapies for } & \multirow[b]{2}{*}{ Case } & \multirow[b]{2}{*}{ No. } & \multirow[b]{2}{*}{ Sex } & \multirow[b]{2}{*}{ Age } & \multirow[b]{2}{*}{ Diagnosis } & \multicolumn{2}{|c|}{ Therapies for } \\
\hline & & & & & OP & RA & & & & & & OP & RA \\
\hline 1 & 1 & $\mathrm{~F}$ & 64 & $\mathrm{RA}, \mathrm{FN}$ & & MTX, TAC & 1 & 12 & $\mathrm{~F}$ & 27 & OA; trauma & & \\
\hline 2 & 2 & $\mathrm{~F}$ & 87 & $\mathrm{RA}, \mathrm{OP}$ & $\mathrm{BP}$ & BUC & 2 & 13 & $\mathrm{~F}$ & 43 & $\mathrm{RA}, \mathrm{OP}$ & $\mathrm{BP}$ & ETN, MTX, PSL \\
\hline 3 & 3 & $\mathrm{~F}$ & 76 & RA, FN, OP & $\mathrm{BP}$ & MTX, SASP & 3 & 14 & $\mathrm{~F}$ & 57 & RA & & TCZ \\
\hline 4 & 4 & M & 78 & $\mathrm{RA}$ & & BUC, PSL & 3 & 15 & $\mathrm{~F}$ & 57 & RA & & TCZ \\
\hline 5 & 5 & $\mathrm{~F}$ & 77 & RA, FN, OP & $\mathrm{BP}$ & SASP, PSL & 4 & 16 & $\mathrm{~F}$ & 62 & RA & & PSL \\
\hline 6 & 6 & $\mathrm{~F}$ & 55 & $\mathrm{RA}, \mathrm{OP}$ & $\mathrm{BP}$ & MTX, BUC, PSL & 5 & 17 & $\mathrm{~F}$ & 73 & RA, FN & & PSL \\
\hline 7 & 7 & $M$ & 56 & $\mathrm{FN}$ & & & 6 & 18 & $\mathrm{~F}$ & 77 & FN, OP & $\mathrm{BP}$ & \\
\hline 8 & 8 & $\mathrm{~F}$ & 86 & FN, OP & Vit.D & & 7 & 19 & $\mathrm{~F}$ & 80 & RA, OP & $\mathrm{BP}$ & BUC, PSL \\
\hline 9 & 9 & $\mathrm{~F}$ & 75 & FN, OP & & & 8 & 20 & $\mathrm{~F}$ & 82 & $\mathrm{RA}, \mathrm{OP}$ & $\mathrm{BP}$ & ETN, MTX, PSL \\
\hline 10 & 10 & $M$ & 83 & $\mathrm{FN}, \mathrm{OP}$ & & & 9 & 21 & M & 60 & RA; excluded & & MTX \\
\hline 11 & 11 & $\mathrm{~F}$ & 90 & $\mathrm{FN}, \mathrm{OP}$ & & & & & & & & & \\
\hline
\end{tabular}

FMiS, forming minimodeling structure; No., number of specimens; F, female; $M$, male; RA, rheumatoid arthritis; FN, femoral neck fracture; OA, osteoarthritis; OP, osteoporosis; BP, bisphosphonate; Vit.D, vitamin D; MTX, methotrexate; TAC, tacrolimus; BUC, bucillamine; SASP, sulfasalazine; PSL, prednisolone; IFX, infliximab; ETN, etanercept;

TCZ, tocilizumab.

bisphosphonate therapies for OP (No. 2, 3, 5, 6, 13, and 18-20). Among 13 specimens from 12 patients with RA, 4 specimens were from femoral head replacement as a treatment for FN (No. 1, 3, 5, and 17), and 9 were from total hip arthroplasty performed due to RA-related destruction of the hip joint (No. 2, 4, 6, 13-16, 19, and 20). The remaining seven specimens were obtained from $\mathrm{FN}$ in patients with OP (No. 8-11 and 18), trauma (No. 7), and secondary OA due to a traumatic hip joint dislocation (No. 12).

\section{Histomorphometric Data in FMiS-Positive and -Negative Groups}

At least 1 FMiS was identified in 9 of our 20 specimens (45\%), and we called this group FMiS-positive. These nine specimens were from eight individuals. The analysis of consecutive sections among one of this group showed that the FMiS grew and connected to the adjacent trabecular bone (Figures 2I-K; Video S1 in Supplementary Material).

There were no significant differences in age $(62.0 \pm 18.4$ vs. $75.2 \pm 12.0 ; p=0.12)$ and BMI $(21.2 \pm 2.8$ vs. $23.3 \pm 6.5 ; p=0.90)$ between FMiS-positive and -negative groups. In histomorphometric data, the FMiS-positive group showed that BV/TV and the static formation parameters were significantly higher than those of FMiS-negative group [BV/TV $31.7 \pm 10.2$ vs. $23.1 \pm 3.9 \%$ $(p<0.05) ; \mathrm{OV} / \mathrm{BV}, 2.1 \pm 1.6$ vs. $0.6 \pm 0.3 \%(p<0.001)$; OS/ BS, $23.6 \pm 15.5$ vs. $7.6 \pm 4.2 \%(p<0.001)$; and O.Th, $7.4 \pm 2.0$ vs. $5.2 \pm 1.0 \mu \mathrm{m}(p<0.05)]$. However, there were no significant differences between FMiS-positive group and -negative group in Tb.Th $(186.1 \pm 49.2$ vs. $156.2 \pm 21.0 \mu \mathrm{m} ; p=0.11)$ and ES/BS $(1.9 \pm 1.4$ vs. 1.6 vs. $1.2 \% ; p=0.86)$ (Figure 3$)$. The N.FMiS and N.FMiS/BS ranged from 1 to 10 and $2.1 \times 10^{-6}$ to $3.0 \times 10^{-5} / \mu \mathrm{m}$, respectively, which did not show significant correlation with histological variables of osteoid parameters (OV/BV, OS/BS, and $\mathrm{O} . \mathrm{Th}$ ) in FMiS-positive group (data not shown). The average values of BV (FMiS)/BV and BS (FMiS)/BS were $0.1 \%\left(1.7 \times 10^{-2}\right.$ to $0.2 \%)$ and $0.8 \%(0.1-1.5 \%)$, while the average values of $\mathrm{BV}$ (FMiS)/OV and BS (FMiS)/OS were 5.4\% (0.7-9.1\%) and 3.8\% (1.4-10.9\%), respectively.

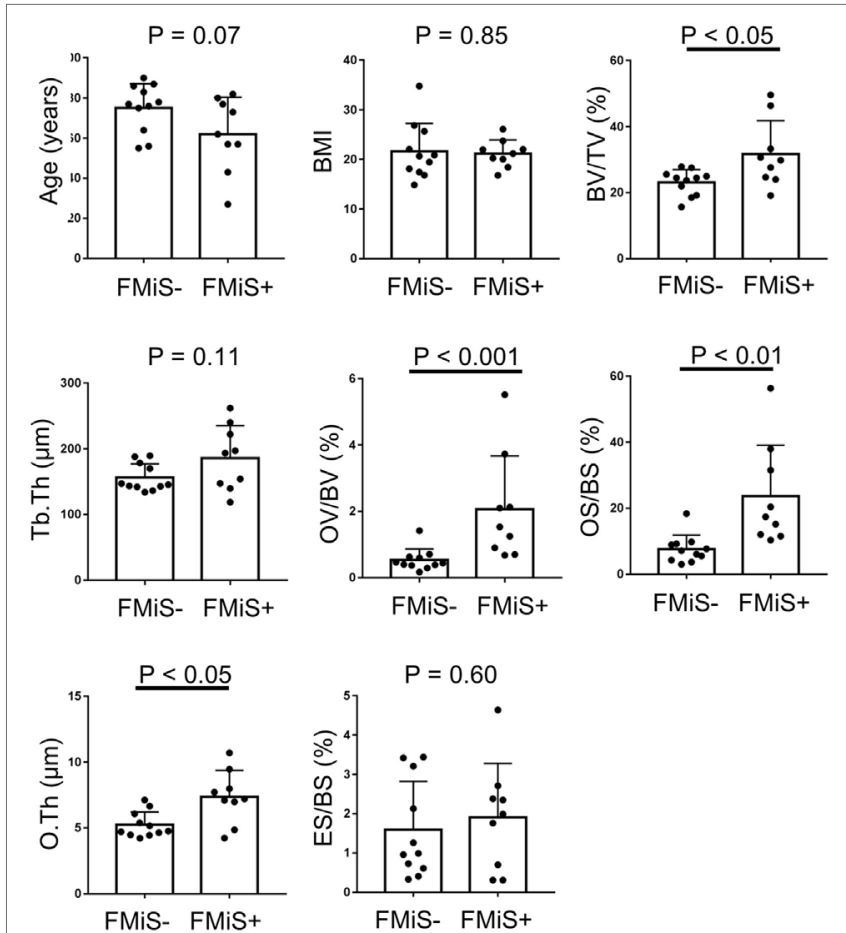

FIGURE 3 | Comparison between FMiS-positive and -negative specimens. FMiS-positive group (FMiS+) showed significantly higher values in bone histomorphometric data (BV/TV, OV/BV, OS/BS, and O.Th) compared with FMiS-negative group (FMiS-). Data are mean \pm SD. Abbreviations: FMiS, forming minimodeling structure; BMI, body mass index; BV, bone volume; TV, tissue volume; Tb.Th, trabecular thickness; OV, osteoid volume; BV, bone volume; OS, osteoid surface; BS, bone surface; O.Th, osteoid thickness; ES, eroded surface.

\section{Histomorphometric Data in RA Specimens}

Forming minimodeling structures were identified in 7 of our 13 specimens (54\%) from 6 of 12 individuals. Comparing FMiS-positive with -negative groups, there were no significant 
differences in age $(64.9 \pm 14.1$ vs. $72.8 \pm 11.4 ; p=0.42)$, BMI $(21.1 \pm 1.7$ vs. $22.9 \pm 7.1 ; p=0.82)$, DAS28-ESR3 $(2.9 \pm 0.5$ vs. $3.1 \pm 1.0 ; p=0.42)$, CRP $(0.6 \pm 0.7$ vs. $0.6 \pm 0.7 \mathrm{mg} / \mathrm{dL}$; $p=0.81)$, MMP-3 (136.0 \pm 115.4 vs. $170.9 \pm 186.3 \mathrm{ng} / \mathrm{mL}$; $p=0.99)$, and PSL intake (5.0 \pm 5.2 vs. $2.7 \pm 3.9 ; p=0.99)$. In histomorphometric data, FMiS-positive group showed that statistic formation parameters were significantly higher than those of the FMiS-negative group: OV/BV, $2.4 \pm 1.7$ vs. $0.3 \pm 0.1 \%$ $(p<0.01)$; OS/BS, $26.6 \pm 16.5$ vs. $5.0 \pm 1.6 \%(p<0.01)$; and O.Th, $7.8 \pm 1.9$ vs. $5.7 \pm 1.1 \mu \mathrm{m}(p<0.05)$. However, there were no significant differences between FMiS-positive and -negative groups in BV/TV ( $31.4 \pm 8.7$ vs. $25.3 \pm 2.2 \%$; $p=0.10)$, Tb.Th $(180.8 \pm 44.6$ vs. $169.8 \pm 19.5 \mu \mathrm{m} ; p=0.53)$, and $\mathrm{ES} / \mathrm{BS}(2.4 \pm 1.2$ vs. 2.0 vs. $1.5 \%$; $p=0.95$ ) (Figure 4). Six out of 7 in FMiS-positive specimens showed that the reason for hip surgery was hip joint destruction (86\%). Of the 9 RA specimens from hip joint destruction patients, 6 (67\%) were positive for FMiSs (Table 1). The comparison between this FMiS-positive $(n=6)$ and -negative groups $(n=3)$ showed that OV/BV $(1.7 \pm 1.5$ vs. $0.4 \pm 0.1 \%$; $p<0.05)$ and $\mathrm{OS} / \mathrm{BS}(29.3 \pm 16.3$ vs. $5.5 \pm 1.7 \%$; $p<0.05)$ were significantly increased in FMiS-positive group, while there were no statistically significant differences in age, BMI, DAS28-ESR3, CRP, MMP-3, PSL intake, BS, BV, TV, BV/TV, Tb.Th, O.Th, and ES/BS (data not shown).

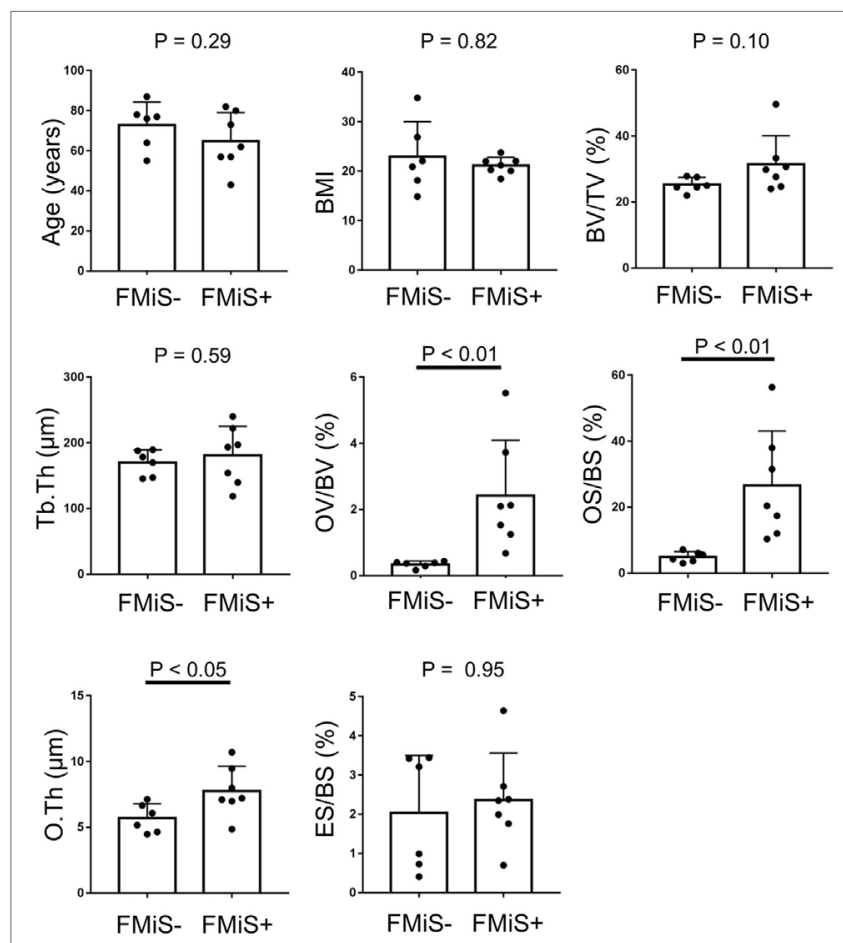

FIGURE 4 | Comparison between FMiS-positive and -negative specimens from patients with RA. FMiS-positive (FMiS+) group showed significantly higher values in bone histomorphometric data (OV/BV, OS/BS, and O.Th) compared with FMiS-negative group (FMiS-). Data are mean \pm SD.

Abbreviations: FMiS, forming minimodeling structure; BMl, body mass index; BV, bone volume; TV, tissue volume; Tb.Th, trabecular thickness; OV, osteoid volume; BV, bone volume; OS, osteoid surface; BS, bone surface; O.Th, osteoid thickness; ES, eroded surface.

\section{DISCUSSION}

The establishment of a definition for the histological finding of modeling-based bone formation is important for evaluating bone histology. Here, we clarified the definition of minimodeling structures (MiS), and described new histological criteria for identifying them in their active forming state, which we now define as, "forming minimodeling structures" (FMiS). Trans iliac biopsies from postmenopausal women were previously examined for evidence of modeling-based bone formation, which we call MiSs in this study. The percentage of patients with MiSs varied from 0 to $63 \%(7,9,10)$, and in those treated with human PTH it was $0.4-40.0 \%(9,10)$. This confirms a wide range probably due to the vague definition of minimodeling in histological findings and the difficulty in MiSs to be distinguished from the old lamellar bone. In contrast the demarcation of an FMiS which is covered with an osteoid seam is clear. Therefore, an important aspect of the present paper is to define these FMiSs, where ongoing surface osteoid gives additional information on forming surfaces. Our findings identified the presence of FMiSs in 9 out of 20 specimens (45\%), providing strong evidence for modeling-based bone formation on trabeculae in loaded femoral head bone even in the elderly. Moreover, we demonstrated that FMiSs were highly prevalent in specimens with high static formation parameters. The cause of hip surgery in FMiS-positive was joint destruction in 7 out of $9(78 \%)$ in total specimens, and 6 out of 7 (86\%) in RA specimens (Table 1). This suggests that the appearance of FMiSs may associate more with joint destruction than with femoral neck fracture. Therefore, we conducted the subsequent analysis in specimens from patients with RA who had hip surgery due to joint destruction. Again these results showed higher values of OV/BV and OS/BS in FMiS-positive than in -negative group. FMiS-positive specimens showed that the average of BV (FMiS)/OV and BS (FMiS)/OS were 5.4 and $3.8 \%$, which were 50 times and 4 times higher in that of $\mathrm{BV}$ (FMiS)/BV and BS (FMiS)/BS, respectively. This was also compatible with FMiSs being associated with higher values of osteoid parameters.

This finding of FMiSs is quite different from that seen in pathological conditions such as osteomalacia $(28,29)$ or hypophosphatasia (30); all of our specimens showed a lamellar pattern in the FMiS itself, distinct from the underlying trabecular bone. The histological analysis revealed the normal range of osteoid thickness $(<12 \mu \mathrm{m})$, and no scalloped appearance in specimens with FMiSs.

The analysis of consecutive sections with FMiS-positive clearly showed that new bone grew from a bone surface without previous bone resorption and connected with the adjacent trabecular bone (Figures 2I-K; Video S1 in Supplementary Material). We consider this connection process is the mechanism for the increase in connectivity as an adaptation to increased mechanical stimuli, as others hypothesized for the process of minimodeling $(2,31,32)$. Although we did not measure the connectivity of trabecular bone in each sample with $\mu \mathrm{CT}$ images $(33,34)$ in this study, Kazama et al. (35) reported that trabecular bone volume (BV/TV) is correlated with trabecular bone connectivity. In our study, FMiS-positive group showed a 
high value of BV/TV compared with -negative group (Figure 3) and a tendency in RA specimens (Figure 4), indicating FMiSpositive specimens are associated with an increase in connectivity of trabecular bone.

How the process of FMiSs is regulated still remains unclear. Among nine specimens from patients with RA who underwent total hip replacement, $67 \%$ showed the modeling-based bone formation on trabecular bone surfaces (No. 13-16, 19, 20). Conversely, among five specimens from elderly patients with low impact hip fracture (No. 8-11, 18), only one specimen showed FMiSs (20\%; No. 18) (Table 1). We did not observe statistical differences in age and BMI between these two groups (63.5 \pm 15.0 vs. $78.0 \pm 13.5 ; p=0.18,21.3 \pm 2.0$ vs. $20.0 \pm 3.5 ; p=0.19$ respectively). Whether inflammatory arthritis is associated with ongoing modeling-based bone formation in the central femoral head is a challenging issue that needs to be addressed through a larger study of specimens from RA and non-arthritic conditions. Various functions of osteocytes in bone metabolism have been revealed so far (36-40). There is accumulating evidence of the involvement of sclerostin in the anabolic response within trabecular bone, which is regulated by the mechanical loading through the reduction of sclerostin positive osteocytes $(41,42)$. From the analysis of serum bone turnover markers, the antisclerostin antibody has been reported to increase bone formation via a process of modeling-based bone formation $(43,44)$. Although speculative, it is possible that the decrease in expression of sclerostin by osteocytes may play a key role in FMiSs. Nazarian et al. showed that femoral head trabeculae are highly loaded in habitual daily activities (45), however, it remains to be elucidated how such high loading conditions translate into building FMiSs.

The reason why N.FMiS/BS did not show significant correlation with the histological variables of osteoid parameters in the FMiS-positive group is probably due to the small number of specimens. We cannot exclude the possibility that FMiS would be a peripheral part of the remodeling-based bone structure, already reported as "spill over" (10), or of a mature phase of micro callus (46-51). To consider these theories, studies with larger numbers and use of consecutive sections are necessary. Other weaknesses of the present study include the lack of fluorescent double labels for assessing dynamic formation parameters, and of data about serum bone turnover markers (CTX and P1NP), 25(OH)D, and $\mathrm{PTH}$ as well as bone mineral density in each patient. The values of O.Th in our specimens were all within normal range, unlike osteomalacia, it would be useful to know 25(OH)D and PTH levels in order to exclude the possibility of mild insufficiency and secondary hyperparathyroid effects (52). Despite these limitations, we were able to confirm the presence of the FMiSs in individuals with higher values of static bone formation parameters. Further studies are needed to address the spatial location of the FMiSs with relation to their physiological and pathological microenvironment.

Our findings provide further evidence that modeling-based bone formation on trabecular bone, which is different from the process of remodeling-based bone formation, continues even in the elderly, and that FMiSs can be a predictive indicator in bone specimens for higher values of osteoid parameters.

\section{ETHICS STATEMENT}

Ethics Committee at Niigata University School of Medicine approved this research on January 4, 2012 (Protocol Identification Number 1345), and Ethics committee of Niigata Rehabilitation Hospital approved this protocol on February 20, 2012 at the fifth 2012 Ethics committee.

\section{AUTHOR CONTRIBUTIONS}

All contributing authors have agreed to submission of this manuscript for publication. HS, NK, NY, HT, and NE conceived and designed the study. HS, NK, TS, JF, YK, TK, and NY performed experiments. HS, NK, TS, and YK analyzed data. HS, KP, NY, HT, and NE interpreted results and wrote the manuscript.

\section{ACKNOWLEDGMENTS}

The authors thank Dr. L. Skingle (Cambridge University of Bone Research Group in Department of Medicine) for helpful discussions.

\section{FUNDING}

This study was supported by a Grant-in-Aid for Scientific Research from the Ministry of Education, Culture, Sports, Science and Technology (25462363), Japan Rheumatism Foundation, Foundation of Kyowakai in Niigata University, and JA Niigata Prefectural Welfare Federation of Agricultural Cooperative. Dr. K. Poole acknowledges the funding support of the NIHR Cambridge Biomedical Research Centre.

\section{SUPPLEMENTARY MATERIAL}

The Supplementary Material for this article can be found online at https://www.frontiersin.org/articles/10.3389/fendo.2018.00088/ full\#supplementary-material.

FIGURE S1 | Comparison with contact radio micrograph. A figure of contact radio micrograph from the half cross-section of the second metatarsal bone, which was collected from a 72-year-old woman who underwent osteotomy due to hallux valgus deformity (100 $\mu \mathrm{m}$ in thickness with a polished section) (A). A figure of fluorescent microscopy after Villanueva bone staining from an adjacent bone area (25 $\mu \mathrm{m}$ in thickness with a polished section) (B). Low mineralization area (grey) in contact radio micrograph (A) corresponds with low fluorescent signal (green) area in secondary osteon by fluorescent microscopy analysis (B). Scale bar: $300 \mu \mathrm{m}$.

VIDEO S1 | Reconstructive video of FMiS from 30 consecutive sections. This video is a representation of the FMiS from 30 serial sections under fluorescence microscopy, which shows the FMiS grows and connects to adjacent trabecular bone to form a bridge. This video is from the same specimens as Figures 1I-K. 


\section{REFERENCES}

1. Frost HM. Bone dynamics in metabolic bone disease. J Bone Joint Surg Am (1966) 48(6):1192-203. doi:10.2106/00004623-196648060-00018

2. Frost HM. Skeletal structural adaptations to mechanical usage (SATMU): 1. Redefining Wolff's law: the bone modeling problem. Anat Rec (1990) 226(4):403-13. doi:10.1002/ar.1092260402

3. Boyde A. The real response of bone to exercise. J Anat (2003) 203(2):173-89. doi:10.1046/j.1469-7580.2003.00213.x

4. Taylor AM, Boyde A, Davidson JS, Jarvis JC, Ranganath LR, Gallagher JA. Identification of trabecular excrescences, novel microanatomical structures, present in bone in osteoarthropathies. Eur Cell Mater (2012) 23:300-8. doi:10.22203/eCM.v023a23

5. Parfitt AM. Osteonal and hemi-osteonal remodeling: the spatial and temporal framework for signal traffic in adult human bone. J Cell Biochem (1994) 55(3):273-86. doi:10.1002/jcb.240550303

6. Borgiani E, Duda GN, Checa S. Multiscale modeling of bone healing: toward a systems biology approach. Front Physiol (2017) 8:287. doi:10.3389/fphys.2017.00287

7. Kobayashi S, Takahashi HE, Ito A, Saito N, Nawata M, Horiuchi H, et al. Trabecular minimodeling in human iliac bone. Bone (2003) 32(2):163-9. doi:10.1016/S8756-3282(02)00947-X

8. Jee WS, Tian XY, Setterberg RB. Cancellous bone minimodeling-based formation: a Frost, Takahashi legacy. J Musculoskelet Neuronal Interact (2007) 7(3):232-9.

9. Ma YL, Zeng Q, Donley DW, Ste-Marie LG, Gallagher JC, Dalsky GP, et al. Teriparatide increases bone formation in modeling and remodeling osteons and enhances IGF-II immunoreactivity in postmenopausal women with osteoporosis. J Bone Miner Res (2006) 21(6):855-64. doi:10.1359/jbmr.060314

10. Lindsay R, Cosman F, Zhou H, Bostrom MP, Shen VW, Cruz JD, et al. A novel tetracycline labeling schedule for longitudinal evaluation of the short-term effects of anabolic therapy with a single iliac crest bone biopsy: early actions of teriparatide. J Bone Miner Res (2006) 21(3):366-73. doi:10.1359/jbmr.051109

11. Yajima A, Inaba M, Tominaga Y, Tanaka M, Otsubo S, Nitta K, et al. Impact of lanthanum carbonate on cortical bone in dialysis patients with adynamic bone disease. TherApherDial(2013) 17(Suppl1):41-8.doi:10.1111/1744-9987.12038

12. Yajima $\mathrm{A}$, Inaba $\mathrm{M}$, Tominaga $\mathrm{Y}$, Ito $\mathrm{A}$. Bone formation by minimodeling is more active than remodeling after parathyroidectomy. Kidney Int (2008) 74(6):775-81. doi:10.1038/ki.2008.242

13. Yajima A, Inaba M, Tominaga Y, Ito A. Minimodeling reduces the rate of cortical bone loss in patients with secondary hyperparathyroidism. Am J Kidney Dis (2007) 49(3):440-51. doi:10.1053/j.ajkd.2006.11.045

14. Ubara Y, Tagami T, Nakanishi S, Sawa N, Hoshino J, Suwabe T, et al. Significance of minimodeling in dialysis patients with adynamic bone disease. Kidney Int (2005) 68(2):833-9. doi:10.1111/j.1523-1755.2005.00464.x

15. Ubara Y, Fushimi T, Tagami T, Sawa N, Hoshino J, Yokota M, et al. Histomorphometric features of bone in patients with primary and secondary hypoparathyroidism. Kidney Int (2003) 63(5):1809-16. doi:10.1046/j. 1523-1755.2003.00916.x

16. Zhou H, Ma YF, Yao W, Cui L, Setterberg R, Liang CT, et al. Lumbar vertebral cancellous bone is capable of responding to PGE2 treatment by stimulating both modeling and remodeling-dependent bone gain in aged male rats. Calcif Tissue Int (2001) 68(3):179-84. doi:10.1007/s002230001207

17. Saito H, Takeda S, Amizuka N. Eldecalcitol and calcitriol stimulates 'bone minimodeling, focal bone formation without prior bone resorption, in rat trabecular bone. J Steroid Biochem Mol Biol (2013) 136:178-82. doi:10.1016/j. jsbmb.2012.10.004

18. Erben RG. Vitamin D analogs and bone. J Musculoskelet Neuronal Interact (2001) 2(1):59-69.

19. Skedros JG, Holmes JL, Vajda EG, Bloebaum RD. Cement lines of secondary osteons in human bone are not mineral-deficient: new data in a historical perspective. Anat Rec A Discov Mol Cell Evol Biol (2005) 286(1):781-803. doi:10.1002/ar.a.20214

20. Yamaguchi K, Croucher PI, Compston JE. Comparison between the lengths of individual osteoid seams and resorption cavities in human iliac crest cancellous bone. Bone Miner (1993) 23(1):27-33. doi:10.1016/ S0169-6009(08)80088-8

21. Villanueva AR. A bone stain for osteoid seams in fresh, unembedded, mineralized bone. Stain Technol (1974) 49(1):1-8. doi:10.3109/10520297409116928
22. Hanyu T, Chotanaphuti T, Arai K, Tanaka T, Takahashi HE. Histomorphometric assessment of bone changes in rats with type II collagen-induced arthritis. Bone (1999) 24(5):485-90. doi:10.1016/S8756-3282(99)00006-X

23. Hanyu T, Arai K, Takahashi HE. Structural mechanisms of bone loss in iliac biopsies: comparison between rheumatoid arthritis and postmenopausal osteoporosis. Rheumatol Int (1999) 18(5-6):193-200. doi:10.1007/s002960050084

24. Parfitt AM, Drezner MK, Glorieux FH, Kanis JA, Malluche H, Meunier PJ, et al. Bone histomorphometry: standardization of nomenclature, symbols, and units. Report of the ASBMR Histomorphometry Nomenclature Committee. J Bone Miner Res (1987) 2(6):595-610. doi:10.1002/jbmr.5650020617

25. Dempster DW, Compston JE, Drezner MK, Glorieux FH, Kanis JA, Malluche H, et al. Standardized nomenclature, symbols, and units for bone histomorphometry: a 2012 update of the report of the ASBMR Histomorphometry Nomenclature Committee. J Bone Miner Res (2013) 28(1):2-17. doi:10.1002/ jbmr.1805

26. Tamhane A, Redden DT, McGwin G Jr, Brown EE, Westfall AO, Reynolds RJ, et al. Comparison of the disease activity score using erythrocyte sedimentation rate and C-reactive protein in African Americans with rheumatoid arthritis. J Rheumatol (2013) 40(11):1812-22. doi:10.3899/jrheum.121225

27. Inoue E, Yamanaka H, Hara M, Tomatsu T, Kamatani N. Comparison of Disease Activity Score (DAS)28- erythrocyte sedimentation rate and DAS28C-reactive protein threshold values. Ann Rheum Dis (2007) 66(3):407-9. doi:10.1136/ard.2006.054205

28. Rehman MT, Hoyland JA, Denton J, Freemont AJ. Age related histomorphometric changes in bone in normal British men and women. J Clin Pathol (1994) 47(6):529-34. doi:10.1136/jcp.47.6.529

29. Recker RR, Kimmel DB, Parfitt AM, Davies KM, Keshawarz N, Hinders S. Static and tetracycline-based bone histomorphometric data from 34 normal postmenopausal females. J Bone Miner Res (1988) 3(2):133-44. doi:10.1002/ jbmr.5650030203

30. Barvencik F, Beil FT, Gebauer M, Busse B, Koehne T, Seitz S, et al. Skeletal mineralization defects in adult hypophosphatasia - a clinical and histological analysis. Osteoporos Int (2011) 22(10):2667-75. doi:10.1007/s00198-011-1528-y

31. Jee WS, Li XJ. Adaptation of cancellous bone to overloading in the adult rat: a single photon absorptiometry and histomorphometry study. Anat Rec (1990) 227(4):418-26. doi:10.1002/ar.1092270405

32. Frost HM. A determinant of bone architecture. The minimum effective strain. Clin Orthop Relat Res (1983) 175:286-92.

33. Genant HK, Engelke K, Prevrhal S. Advanced CT bone imaging in osteoporosis. Rheumatology (2008) 47(Suppl 4):iv9-16. doi:10.1093/rheumatology/ ken 180

34. Bouxsein ML, Boyd SK, Christiansen BA, Guldberg RE, Jepsen KJ, Muller R. Guidelines for assessment of bone microstructure in rodents using microcomputed tomography. J Bone Miner Res (2010) 25(7):1468-86. doi:10.1002/ jbmr.141

35. Kazama JJ, Koda R, Yamamoto S, Narita I, Gejyo F, Tokumoto A. Cancellous bone volume is an indicator for trabecular bone connectivity in dialysis patients. Clin J Am Soc Nephrol (2010) 5(2):292-8. doi:10.2215/cjn.04150609

36. Saini V, Marengi DA, Barry KJ, Fulzele KS, Heiden E, Liu X, et al. Parathyroid hormone $(\mathrm{PTH}) / \mathrm{PTH}$-related peptide type 1 receptor $(\mathrm{PPR})$ signaling in osteocytes regulates anabolic and catabolic skeletal responses to PTH. J Biol Chem (2013) 288(28):20122-34. doi:10.1074/jbc.M112.441360

37. Maycas M, Ardura JA, de Castro LF, Bravo B, Gortazar AR, Esbrit P. Role of the parathyroid hormone type 1 receptor (PTH1R) as a mechanosensor in osteocyte survival. J Bone Miner Res (2015) 30(7):1231-44. doi:10.1002/ jbmr.2439

38. Bonewald LF. The amazing osteocyte. J Bone Miner Res (2011) 26(2):229-38. doi:10.1002/jbmr.320

39. Xiong J, Onal M, Jilka RL, Weinstein RS, Manolagas SC, O’Brien CA. Matrixembedded cells control osteoclast formation. Nat Med (2011) 17(10):1235-41. doi: $10.1038 / \mathrm{nm} .2448$

40. Nakashima T, Hayashi M, Fukunaga T, Kurata K, Oh-Hora M, Feng JQ, et al. Evidence for osteocyte regulation of bone homeostasis through RANKL expression. Nat Med (2011) 17(10):1231-4. doi:10.1038/nm.2452

41. Lara-Castillo N, Kim-Weroha NA, Kamel MA, Javaheri B, Ellies DL, Krumlauf RE, et al. In vivo mechanical loading rapidly activates beta-catenin signaling in osteocytes through a prostaglandin mediated mechanism. Bone (2015) 76:58-66. doi:10.1016/j.bone.2015.03.019 
42. Spatz JM, Wein MN, Gooi JH, Qu Y, Garr JL, Liu S, et al. The Wnt inhibitor sclerostin is up-regulated by mechanical unloading in osteocytes in vitro. J Biol Chem (2015) 290(27):16744-58. doi:10.1074/jbc.M114.628313

43. Saag KG, Petersen J, Brandi ML, Karaplis AC, Lorentzon M, Thomas T, et al. Romosozumab or alendronate for fracture prevention in women with osteoporosis. N Engl J Med (2017) 377(15):1417-27. doi:10.1056/NEJMoa1708322

44. Langdahl BL, Libanati C, Crittenden DB, Bolognese MA, Brown JP, Daizadeh NS, et al. Romosozumab (sclerostin monoclonal antibody) versus teriparatide in postmenopausal women with osteoporosis transitioning from oral bisphosphonate therapy: a randomised, open-label, phase 3 trial. Lancet (2017) 390(10102):1585-94. doi:10.1016/s0140-6736(17)31613-6

45. Nazarian A, Muller J, Zurakowski D, Muller R, Snyder BD. Densitometric, morphometric and mechanical distributions in the human proximal femur. J Biomech (2007) 40:2573-9. doi:10.1016/j.jbiomech.2006.11.022

46. Okazaki N, Chiba K, Taguchi K, Nango N, Kubota S, Ito M, et al. Trabecular microfractures in the femoral head with osteoporosis: analysis of microcallus formations by synchrotron radiation micro CT. Bone (2014) 64:82-7. doi:10.1016/j.bone.2014.03.039

47. Banse X, Devogelaer JP, Holmyard D, Grynpas M. Vertebral cancellous bone turn-over: microcallus and bridges in backscatter electron microscopy. Micron (2005) 36(7-8):710-4. doi:10.1016/j.micron.2005.07.012

48. Cheng XG, Nicholson PH, Lowet G, Boonen S, Sun Y, Ruegsegger P, et al. Prevalence of trabecular microcallus formation in the vertebral body and the femoral neck. Calcif Tissue Int (1997) 60(5):479-84. doi:10.1007/ s002239900266
49. Hahn M, Vogel M, Amling M, Ritzel H, Delling G. Microcallus formations of the cancellous bone: a quantitative analysis of the human spine. J Bone Miner Res (1995) 10(9):1410-6. doi:10.1002/jbmr.5650100919

50. Blackburn J, Hodgskinson R, Currey JD, Mason JE. Mechanical properties of microcallus in human cancellous bone. J Orthop Res (1992) 10(2):237-46. doi:10.1002/jor.1100100211

51. Koszyca B, Fazzalari NL, Vernon-Roberts B. Trabecular microfractures. Nature and distribution in the proximal femur. Clin Orthop Relat Res (1989) 244:208-16.

52. Need AG, Horowitz M, Morris HA, Moore R, Nordin C. Seasonal change in osteoid thickness and mineralization lag time in ambulant patients. J Bone Miner Res (2007) 22(5):757-61. doi:10.1359/jbmr.070203

Conflict of Interest Statement: The authors declare that the research was conducted in the absence of any commercial or financial relationships that could be constructed as a potential conflict of interest.

Copyright (c) 2018 Sano, Kondo, Shimakura, Fujisawa, Kijima, Kanai, Poole, Yamamoto, Takahashi and Endo. This is an open-access article distributed under the terms of the Creative Commons Attribution License (CC BY). The use, distribution or reproduction in other forums is permitted, provided the original author $(s)$ and the copyright owner are credited and that the original publication in this journal is cited, in accordance with accepted academic practice. No use, distribution or reproduction is permitted which does not comply with these terms. 